\title{
Ability of Archival Tags to Provide Estimates of Geographical Position Based on Light Intensity
}

\author{
Michael K. Musyl $^{1 *}$, Richard W. Brill ${ }^{2}$, Daniel S. Curran ${ }^{1}$, John S. Gunn ${ }^{3}$, \\ Jason R. Hartog 3 , Roger D. Hill ${ }^{4}$, David W. Welch ${ }^{5}$, J. Paige Eveson ${ }^{5,3}$, \\ Christofer H. Boggs ${ }^{2}$, and Russell E. Brainard ${ }^{2}$ \\ ${ }^{1}$ Joint Institute for Marine and Atmospheric Research, University of Hawaii at Manoa, 2570 \\ Dole St., Honolulu, HI 96822, U.S.A. \\ ${ }^{2}$ National Marine Fisheries Service, Honolulu Lab/Southwest Fisheries Science Center, 2570 \\ Dole St., Honolulu, HI 96822, U.S.A. \\ ${ }^{3}$ CSIRO Marine Research, PO Box 1538, Hobart, Tasmania, 7000, AUSTRALIA \\ ${ }^{4}$ Wildlife Computers, 16150 NE 85 th St., Suite \#226, Redmond, WA 98052, U.S.A. \\ ${ }^{5}$ Fisheries and Oceans Canada, Pacific Biological Station, Nanaimo, British Columbia, V9R \\ 5K6, CANADA \\ *Corresponding author: Mike Musyl, Joint Institute for Marine and Atmospheric Research, \\ University of Hawaii at Manoa, 2570 Dole St., Honolulu, HI 96822, U.S.A., Email: \\ mmusyl@honlab.nmfs.hawaii.edu Phone: 808/5928305 FAX: 808/5928300
}

Key words: archival tags, ambient light level, geoposition algorithm, light attenuation, positional errors, crepuscular, Equinox, pelagic fishes

Abstract: We tested the ability of archival tags and their associated algorithms to estimate geographical position based on ambient light intensity by attaching six tags (three tags each from Northwest Marine Technologies [NMT] and Wildlife Computers [WC]) at different depths to a stationary mooring line in the Pacific Ocean (approx. $166^{\circ} 42^{\prime} \mathrm{W}, 24^{\circ} 00^{\prime} \mathrm{N}$ ), for approximately one year (29Aug-98 to 16-Aug-99). Upon retrieval, one tag each from the two vendors had malfunctioned: from these no data (NMT) or only partial data (WC) could be downloaded. An algorithm onboard the NMT tag automatically calculated geographical positions. For the WC tags, three different algorithms were used to estimate geographical positions from the recorded light intensity data. Estimates of longitude from all tags were significantly less variable than those for latitude. The mean absolute error for longitude estimates from the NMT tags ranged from 0.29 to $0.35^{\circ}$, and for the WC tags from 0.13 to $0.25^{\circ}$. The mean absolute error in latitude estimates from the NMT tags ranged from 1.5 to $5.5^{\circ}$, and for the $\mathrm{WC}$ tags from 0.78 to $3.50^{\circ}$. Ambient weather conditions and water clarity will obviously introduce errors into any geoposition algo- 
rithm based on light intensity. We show that by applying objective criteria to light level data, outliers can be removed and the variability of geographical position estimates reduced. We conclude that, although archival tags are suitable for questions of ocean basin-scale movements, they are not well suited for studies of daily fine scale movement patterns because of the likely magnitude of position estimate errors. For studies of fine scale movements in relation to specific oceanographic conditions, forage densities and distance scales of 100 $\mathrm{km}$ or less, other methods (e.g. acoustic tracking) remain the tool of choice.

\section{INTRODUCTION}

Archival tags are electronic data storage devices that are either surgically implanted or attached to the outside of a fish with an anchoring device (Klimley et al., 1994). Current generations of archival tags can store data from up to four sensors (e.g., internal temperature, external temperature, pressure (i.e., depth), and light intensity) taken at one minute intervals for almost one year. At a slower rate of data acquisition, data can be recorded for up to eight to ten years, depending on battery life and amount of memory. Archival tags have been used to chronicle horizontal and vertical movement patterns, residence time in particular areas, and location of possible spawning areas for a variety of marine fishes (Gunn et al., 1994; Metcalfe and Arnold 1997; Block et al., 1998a; 1998b; Lutcavage et al., 1999).

Although archival tags are valuable and welcome tools for fisheries research, an important consideration in evaluating their utility is the accuracy of the estimates of geographical positions. The use of light data (i.e., times of dawn and dusk) to estimate longitude (from local noon) and latitude (from day length) is not a new concept (Smith and Goodman, 1986; Hill, 1994; Bowditch 1995; Sobel, 1995). However, the application of this idea to estimating geographical positions of fishes carrying archival tags can be problematic because of systematic and random errors resulting from equinoxes, light attenuation with depth, water clarity, weather patterns, accuracy of astronomical algorithms, clock errors, resolution of light sensor, and behavior of animal. Welch and Eveson (1999) recently estimated the accuracy of geographical positions based on light data for archival tags placed on a moving vessel and on submerged mooring lines in the northwest Pacific. Based on their findings, they calculated that average positional errors for tagged animals would be about $140 \mathrm{~km}$ (i.e., standard deviations of $0.9^{\circ}$ in longitude and $1.2^{\circ}$ in latitude). Gunn et al. (1994) compared position estimates based on light readings from archival tags attached to southern bluefin tuna being towed in a sea cage in the open ocean to the true position of the cage at midday. As the maximum depth of the cages was less than $20 \mathrm{~m}$ and the experiment was conducted over a short period in January, the effect of deep 
diving and variations around the equinoxes were not examined in their experiments. However, their calculated positional error was $1.52^{\circ}$ (standard deviation of $0.22^{\circ}$ ) for latitude and $0.54^{\circ}$ (standard deviation of $0.09^{\circ}$ ) for longitude.

To define more accurately the ability of available hardware and software to estimate geographic position from light data, we submerged archival tags from two manufacturers at varying depths on a stationary mooring line in the subtropical North Pacific. We then tested the efficacy of four different algorithms to provide estimates of geographical location from the light level data. We thus define some of the errors inherent in the procedures, and provide a measure of positional error estimates for tags submerged at varying depths. Our intention is to aid researchers in interpreting data recorded from swimming animals.

\section{METHODS AND MATERIALS}

Three archival tags from Northwest Marine Technologies (NMT, Shaw Island, WA, USA, serial Nos. 587, 621, 935) and three from Wildlife Computers (WC, Redmond, WA, model MK 7, serial nos. 97-218, 97-219, 97224) were attached at approximately 20 - $\mathrm{m}$ intervals to a subsurface oceanographic mooring deployed on a 76-m bank in the subtropical North Pacific Ocean (approx. $166^{\circ} 42^{\prime} \mathrm{W}, 24^{\circ} 00^{\prime} \mathrm{N}$ ). Tags were housed in PVC plastic pipe. The light sensor stalk protruded toward the surface through a hole drilled in the pipe. The tags were deployed August 29, 1998, and retrieved August 16, 1999.

For the NMT tags, data from each sensor (two temperatures, pressure, and light intensity) were recorded every $8.5 \mathrm{~min}$ and stored as eight-bit binary integers (i.e., with possible values between 0 and 255). The light sensor was most sensitive to wavelengths near $450 \mathrm{~nm}$. Onboard correction algorithms adjusted recorded light data for temperature variation and light attenuation with depth. The corrected light intensity values were scaled logarithmically, with 15 points per decade intensity (e.g., high noon at sea level on a clear day is about 150 units on this scale). From the light curves, we estimated the effective range of $100 \mathrm{nW} \mathrm{cm}$ to at least $10 \mathrm{~mW} \mathrm{~cm}^{-2}$ (bright sunshine) with a sensitivity of 15 readings/decade. Geolocations for the NMT tags were automatically estimated onboard the tags by a proprietary algorithm. This algorithm employed times of sunrise and sunset to find local noon and thus estimate longitude. The light level data used were taken every $128 \mathrm{~s}$ but recorded in the tag's memory only every $8.5 \mathrm{~min}$. Latitude estimates were based on known temperatures at standard depths (Smith and Goodman, 1986). Poor time resolution of the stored light level data, espe- 
cially during crepuscular transitions (i.e., dawn and dusk), prevented any post-processing of the recorded light level data.

The WC archival tags were set to record data from each of the four channels (depth, light, and two temperatures) every $60 \mathrm{~s}$. Data could be collected at this rate for 353 days before filling the memory, the approximate duration of the experiment. Temperature and depth were measured with 12-bit accuracy, but compressed to 8 bits before storing. Temperature had a resolution of $0.05^{\circ} \mathrm{C}$, depth had a resolution of $0.5 \mathrm{~m}$, and the light sensor recorded values in the range from 0 to 255 , scaled logarithmically with 18 points per decade. The effective range of the light sensor was from bright sunshine to a level 10 decades less bright (150 readings lower). This covered the range from $1 \mathrm{pW} \mathrm{cm}^{-2}$ to $20 \mathrm{~mW} \mathrm{~cm}$ (bright sunshine is approximately $10 \mathrm{~mW}$ $\mathrm{cm}^{-2}$ at sea level). Interference filters were used to make the light sensor sensitive to light only in the $450 \pm 50 \mathrm{~nm}$ wavelength range, and light level was internally corrected for temperature, but not depth. Light level data were downloaded from the WC tags, and geographical positions estimated using three different methods.

\subsection{Method 1: Fixed Reference Light Level Method}

This method was developed in 1993 by CSIRO Marine Research (Hobart, Tasmania, Australia) based on techniques described in Nielsen (1963) and Wilson et al. (1992). It uses a "reference light level" to define times of dawn or dusk. In other words, when light levels equaled the reference light level, this defined a specific "zenith angle" (i.e., the angle between the horizon and the center of the sun's disk). Dawn and dusk were initially determined by finding the periods when light levels were changing most rapidly. Next, an ordinary least squares routine was used to fit a second order polynomial equation to the light data between 100 and 155 light units. The time when light level was equal to the reference light level was determined from the fitted curve. The equation changes daily but remains a second order polynomial with the same independent (i.e., time) and dependent (i.e., light) variables. Standard astronomical formulae were then used to determine position from a specified zenith angle (Wilson et al., 1992, Hill, 1994).

The estimation software was tuned by determining the reference light level and corresponding zenith angles that resulted in estimates closest to the known location of the tags. This empirical optimization was conducted using data collected over ten days of the experiment in November 1998. This time period was chosen because it preceded any biofouling of the light sensor (Fig. 1) and was temporally distant from the autumnal equinox (Sept. 21). 
Once established, the optimal reference light level was kept constant. A light level of 135 units corresponded to a zenith angle of $97^{\circ}$.

Method 1 requires light levels recorded by the individual tags be corrected back to the light level at the surface. This was not possible in this situation because light-depth attenuation coefficients have to be specific for each tag. The data required to generate these coefficients were not available because the tags were kept stationary at specific depths. As a substitute, light data were normalized, so that each tag read similar light values at the same time using the following relationships:

$$
\begin{aligned}
& \hat{\mathrm{L}}_{20}=\mathrm{L}_{20}+15 \\
& \hat{\mathrm{L}}_{40}=\mathrm{L}_{40}+21 \\
& \hat{\mathrm{L}}_{60}=\mathrm{L}_{60}+28
\end{aligned}
$$

where

$\hat{\mathrm{L}}_{20}=$ estimated surface light intensity by the tag at $20 \mathrm{~m}$,

$\hat{\mathrm{L}}_{40}=$ estimated surface light intensity by the tag at $40 \mathrm{~m}$,

$\hat{\mathrm{L}}_{60}=$ estimated surface light intensity by the tag at $60 \mathrm{~m}$,

$\mathrm{L}_{20}=$ light level recorded by the tag at $20 \mathrm{~m}$,

$\mathrm{L}_{40}=$ light level recorded by the tag at $40 \mathrm{~m}$,

$\mathrm{L}_{60}=$ light level recorded by the tag at $60 \mathrm{~m}$.

Because accuracies of geographical position estimates depend on times of sunrise and sunset, any drift in the tags' real-time clocks must be corrected. The realtime clocks in the tags at 20 and $40 \mathrm{~m}$ drifted $2 \mathrm{~min} 38 \mathrm{~s}$ and 2 min $18 \mathrm{~s}$ over the 12 month period (respectively), which are within the expected range. A linear drift of time error was assumed. However, the tag at $60 \mathrm{~m}$ drifted $2 \mathrm{~h}, 22 \mathrm{~min}$, and $24 \mathrm{~s}$. The tag's realtime clock clearly malfunctioned 146 days after deployment. We presumed that the major proportion of the clock error occurred after the $146^{\text {th }}$ day and, for simplicity, we did not correct for drift in the real-time clock of this tag throughout the portion analyzed.

\subsection{Method 2: Dawn and Dusk Symmetry Method}

This method was developed by Roger Hill of Wildlife Computers and is explained in greater detail elsewhere in this volume. Longitude was determined by finding the time of midnight, such that the dawn and dusk curves were maximally symmetrical, allowing for small amounts of relative light level change from dawn to dusk caused by changing cloud cover. By matching the entire curves, this technique avoids errors caused by spurious readings at some standard reference light level. The time of midnight is translated to longitude by multiplying the time by 15 , and factoring in the Equa- 
tion of Time (Meeus, 1991). Latitude was calculated by using data from a day close to the start of the deployment (September 15, 1998) for which the light curves were relatively clean, and creating a translation of observed light level with known angle of sun as measured from the vertical (zenith angle). The zenith angle of the sun can be calculated at specific times of day for a given location from standard astronomical equations (Duffet-Smith, 1988; Meeus, 1991). This translation from light level to zenith angle can then be applied to the rest of the data set, so that for each day there is a plot of zenith angle against time. Latitude was determined by finding the latitude that best matches those zenith angles at the measured times. The advantage of this method is that it can provide estimates of latitude throughout the year (including the equinoxes), although in equatorial waters (as in this experiment), the error in the latitude estimate at the equinoxes becomes large. At higher latitudes, good estimates can be expected all year. Corrections of position estimates for drift in the real-time clocks were performed as in Method 1.

\subsection{Method 3: Variable Reference Light Level Method}

This method was developed by Welch and Eveson (1999). The method is similar to the fixed reference light level method described above, but reference light levels were independently estimated for each day by taking $70 \%$ of that day's average mid-day light level. For each day, the light versus time data taken from a two hour period around sunrise and sunset were fitted with a $4^{\text {th }}$ order polynomial using least squares. Initial estimates of the times of dawn and dusk were taken to be the times at which the fitted curve equalled the reference light level. The estimated times of dawn and dusk were were then refined by repeating the above procedure but this time fitting a $4^{\text {th }}$ order polynomial to data that extended just $15 \mathrm{~min}$ before and after the times of dawn and dusk determined in the first step. A zenith angle of $94^{\circ}$ was assumed to correspond to the derived reference light level. This value was determined without making any reference to the known mooring location, but was taken from a previously published study in which it was found to give reasonably good estimates of geographical position (Welch and Eveson 1999). As in Method 1, based on inspection of light curves for 10 days in November, we later optimised the zenith angle to $94.7^{\circ}$. In this third method, no corrections were applied for light attenuation with depth, as it did not significantly improve location estimates. Corrections of position estimates for drift in the realtime clocks were performed as in Method 1. 


\subsection{Comparison of Geographical Estimates}

In order to compare the two types of archival tags and the three different methods used to estimate positions from the WC tags, we grouped the data by depth and used only data that were common to tags at comparable depths. In other words, the NMT tag at $58 \mathrm{~m}$ was grouped with the $\mathrm{WC}$ at $60 \mathrm{~m}$, and the NMT tag at $24 \mathrm{~m}$ was grouped with the $\mathrm{WC}$ tag at $20 \mathrm{~m}$. As a result, fewer data points were used from the NMT tag at $58 \mathrm{~m}$ because comparable data from the WC tag at $60 \mathrm{~m}$ were unavailable owing to tag failure 225 days after deployment. In Table 1, the only data points rejected were those approximately 10 days before and after the autumnal and spring equinoxes. In Table 2, data points around the autumnal and spring equinoxes were rejected, as well as outliers, based on days with significant asymmetry of light level readings (e.g., days with highly variable cloud cover). The latter criteria for rejection and its application are described in detail elsewhere in this volume. To determine if this technique actually improved estimates, we tested for significant differences between mean absolute errors (i.e. |true position-estimate) for latitude for all data in Table 1 to equivalent data in Table 2 using Student's $t$-test, where $P<0.05$ was considered significant. We also calculated the raw errors (i.e., true position-estimate) to gain insight into the mean positional bias of the overall estimates. Mean raw errors were also tested against a hypothetical mean of zero using a two-tailed test at the $P<0.05$ level (Sokal and Rohlf 1981). Next, to test whether the distribution of raw errors conformed to a normal distribution, we used the Kolmogorov-

Smirnov D test for goodness of Fit (Sokal and Rohlf 1981) at the $P<0.05$ level. Lastly, a nearest neighbor clustering algorithm with Euclidean distances of raw positional errors was used to examine the tag/method combinations for patterns (Pielou 1984).

\section{RESULTS}

Upon retrieval, we found that one NMT tag had failed completely and no data could be downloaded. The reason for failure is unknown. Also, upon retrieval, ship personnel reported that all tags were covered with an algal film and some fouling organisms. The diminution of light level over time is evident in Figure 1 and suggests that biofouling was indeed accumulating on the light stalks. At the end of 12 months submergence, the maximum daily light levels in units defined and recorded by the NMT tag at $24 \mathrm{~m}$ had decreased from 139 to 120 . The maximum daily light levels in units defined and recorded by the NMT tag at $58 \mathrm{~m}$ had decreased from 125 to 102 . Equivalent reductions in maximum daily light levels in units defined and 
recorded by WC tags were 244 to 233,239 to 206, and 236 to 213 for the tags at 20,40, and $60 \mathrm{~m}$, respectively.

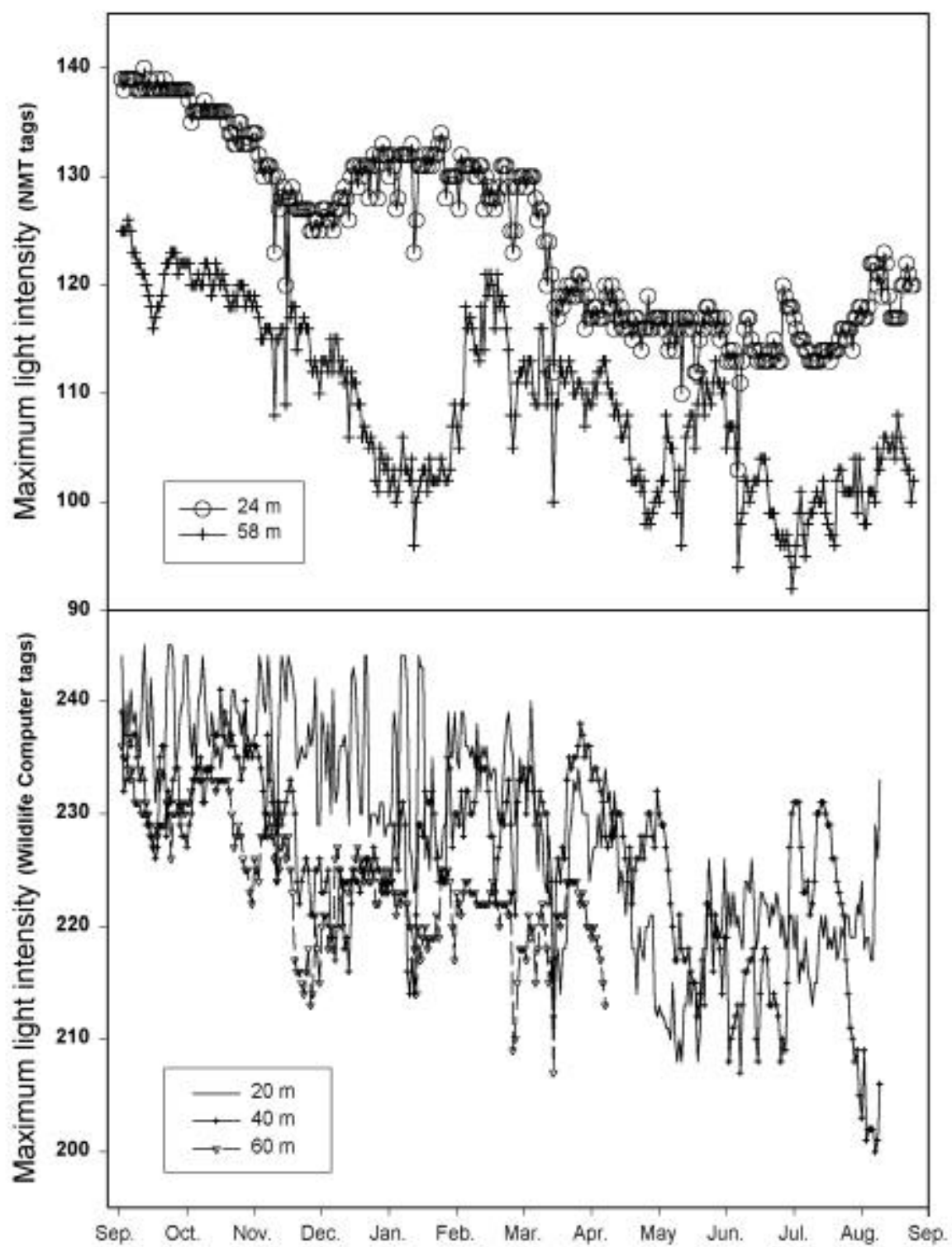

Figure 1. Diminution of maximum light intensity over time for the Northwest Marine Technologies and Wildlife Computers tags. 


\subsection{NMT Tags}

Geographical position estimates from the NMT tags over the entire experimental period are shown in Figure 2. The tags' proprietary algorithm was not able to derive latitude estimates for approximately 18 days around the spring and autumnal equinoxes (March 21 and September 21, respectively). There was more variability in latitude estimates from the tag at $58 \mathrm{~m}$ than the tag at $24 \mathrm{~m}$. The former never fully "recovered" after the spring equinox of 1999. In the temperature records after the spring equinox (not shown), a large discrepancy occurred between readings taken by the thermistor located within the tag body itself and the external thermistor located at the very tip of the fiber optic stalk. The external thermistor was found to be missing when the tag was recovered. It is highly likely that the fiber optic light stalk was also damaged and that the light sensor data were compromised (P. Ekstrom, pers. com.). Damage to the fiber optic light stalk may therefore explain the higher variability in latitude estimates after March on the deeper tag. Another tenable explanation for the variability of geolocations provided by the NMT tag at $58 \mathrm{~m}$ is the sensitivity of the light sensor, which covers about a 5-decade range, as opposed to the WC tag which covers about a 10-decade range.
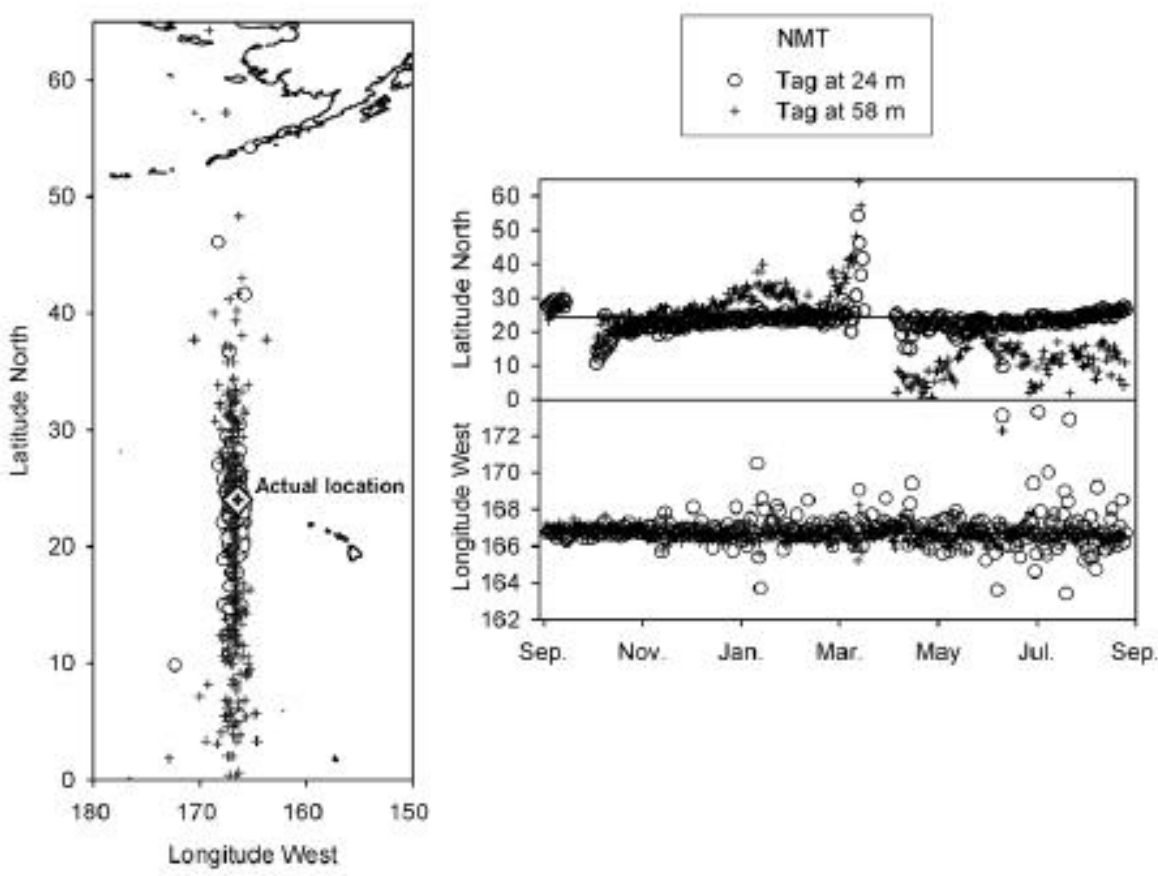

Figure 2. Estimated positions from the Northwest Marine Technologies tags. 
The mean absolute error for latitude was approximately five times greater than that for longitude for the tag at $24 \mathrm{~m}$ (Table 1). For the tag at $58 \mathrm{~m}$ this ratio was approximately ten to one. The tag at $24 \mathrm{~m}$ had a significantly smaller (Student's $t$-test, $P<0.05$ ) mean absolute error for latitude than the tag at $58 \mathrm{~m}$. Mean absolute errors for longitude for the two NMT tags were similar.

\subsection{WC Tags}

Figure 3 shows longitude and latitude estimates for the three WC tags calculated using the fixed reference light level method (Method 1) over the entire experimental period. Figure 4 shows equivalent data derived from the dawn and dusk symmetry method (Method 2), and Figure 5 shows equivalent data from the variable reference light level method (Method 3). As with positional algorithms within NMT tags, all three algorithms applied to the data from the WC tags produced larger positional errors for latitude around the equinoxes than during the remainder of the year. Method 2 exhibited smaller equinox-induced latitude errors than the other two algorithms.

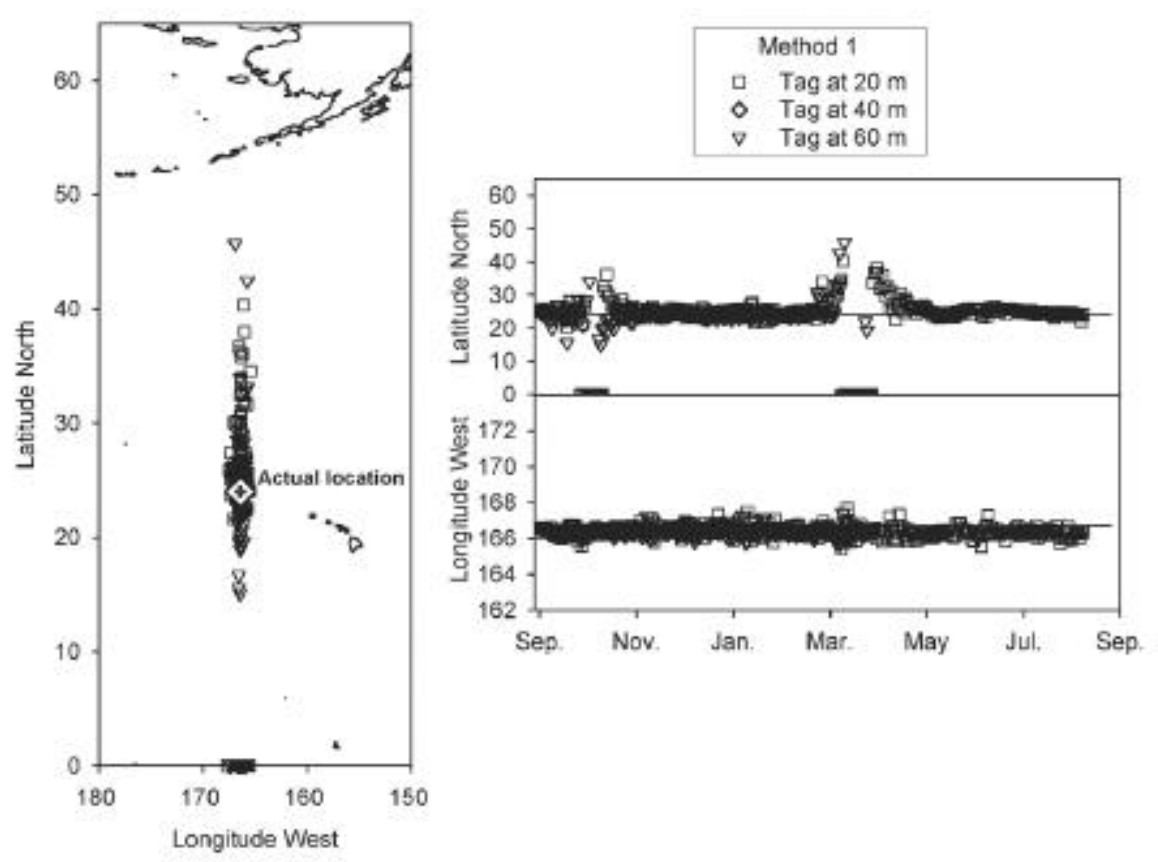

Figure 3. Estimated positions based on data from the Wildlife Computers tags calculated by Method 1. 


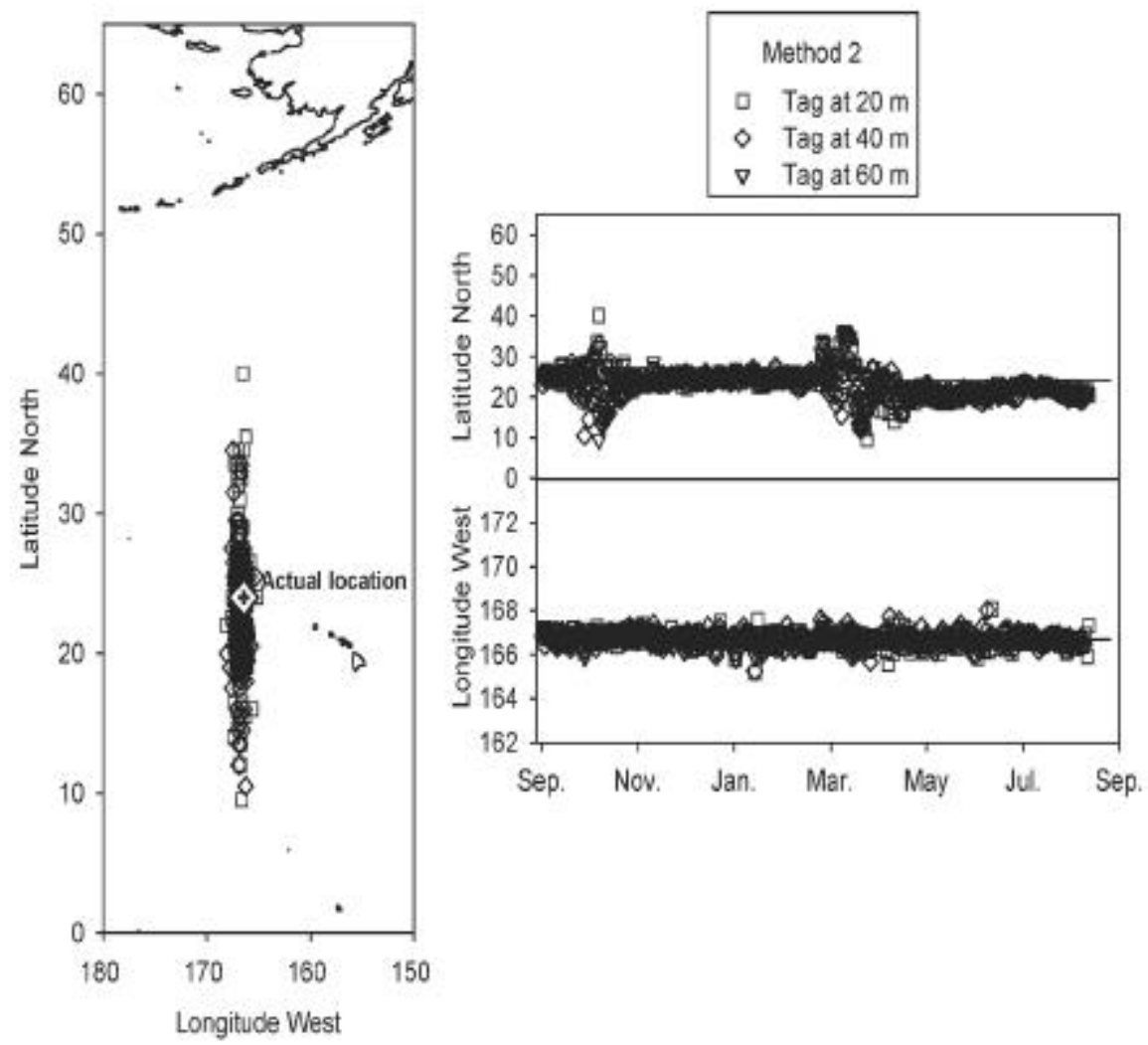

Figure 4. Estimated positions based on data from the Wildlife Computers tags calculated by Method 2.

As with the NMT tags, mean absolute errors for latitude were approximately an order of magnitude larger than those for longitude (Table 1). When data were averaged across the three methods for the WC tags, there were significant differences in errors for latitude by depth (one-way ANOVA, $P<<0.001)$. However, there was no trend by depth. For example, the tag at the intermediate depth had the largest mean absolute error ( $40 \mathrm{~m}$; $2.66 \pm 3.20[$ mean $\pm S D])$, whereas the deepest $(60 \mathrm{~m} ; 1.68 \pm 3.58)$ and the shallowest tag (20 m; $1.68 \pm 1.93)$ were virtually identical ( $t$-test; $P>0.05)$.

Table 2 provides a summary of the mean absolute errors with outliers rejected. By objectively rejecting data based on asymmetry between the dawn and dusk light level curves, the mean absolute errors for latitude were significantly reduced in six of the eleven possible comparisons of equivalent data in Tables 1 and 2. Significant reductions were not observed for the NMT tags at 24 and $58 \mathrm{~m}$; WC tags at 20 and $40 \mathrm{~m}$ were calculated using Method 1, and the WC tag at $20 \mathrm{~m}$ was calculated using Method 3. Mean absolute errors for latitude (e.g., Methods 1 and 3) can be reduced to less 
than $1^{\circ}$, although in most instances mean absolute errors for latitude are reduced only to approximately 1.5 to $3^{\circ}$.

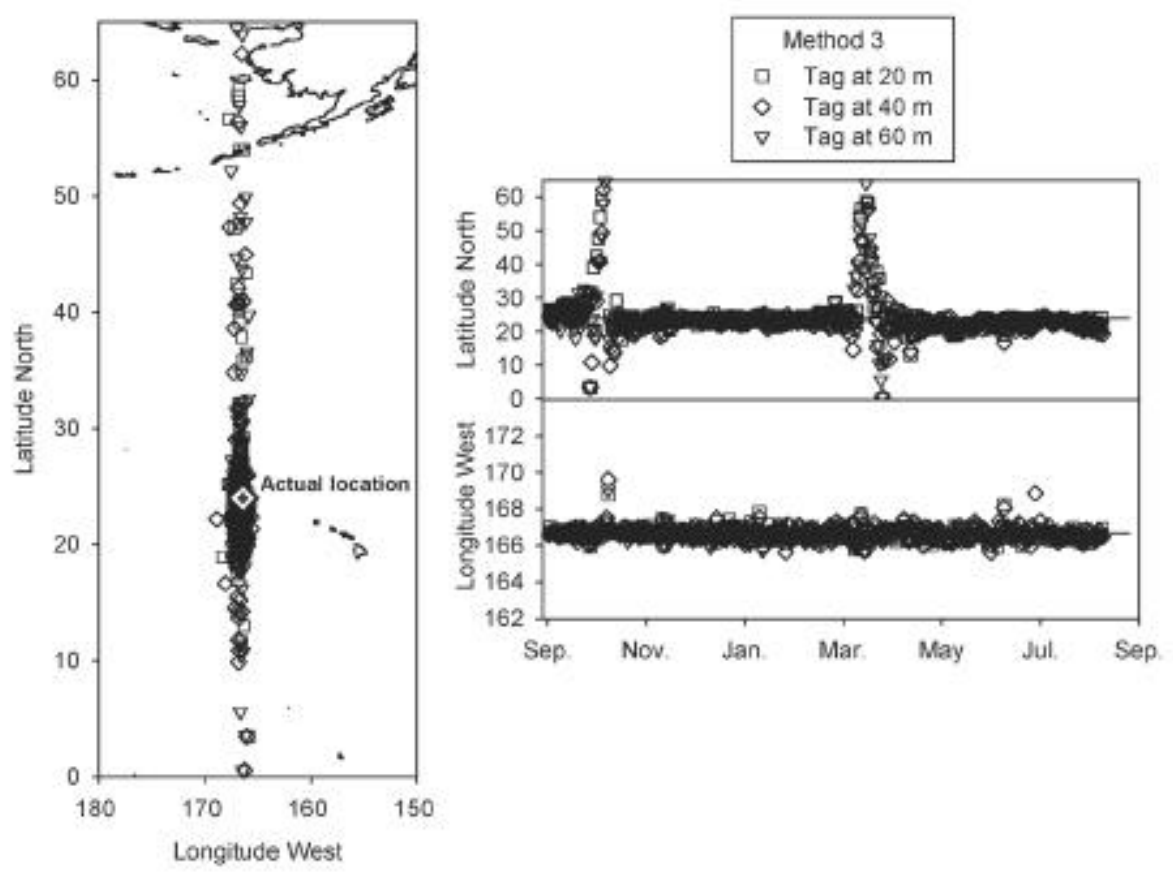

Figure 5. Estimated positions based on data from the Wildlife Computers tags calculated by Method 3 .

The mean positional biases of the raw errors for each tag/method combination are presented in Tables 1 and 2. In Appendix I, we provide a detailed statistical summary of this data. In all tag/method combinations (Tables 1 and 2), mean positional raw errors were not significantly different from a hypothesized mean of zero (two-tailed test, $t<t_{0.05}(2)$, df=n-1). However, in only 6 of 22 cases did the raw longitude errors conform to a normal distribution (Kolmogorov-Smirnov D test for goodness of fit, $P>0.05$ ). None of the raw latitude errors were normally distributed. Except in one instance (i.e., Method 3, tag at $60 \mathrm{~m}$ ), the outlier rejection technique used herein did not alter the mean positional bias of the tag/method combinations (Table 2). It did, however, quite dramatically impact the distribution of raw errors in 6 out of 17 cases including three latitude estimates (NMT tag at $58 \mathrm{~m}$; Method 1, tag at $60 \mathrm{~m}$; Method 3 , tag at $20 \mathrm{~m}$ ) and three longitude estimates (Method 1, tag at $20 \mathrm{~m}$ and two of the tags using Method 3). Longitude errors using Method 2 were normally distributed before and after outlier rejection, as was the case for two of the tags using Method 1 and one tag for Method 3 (Table 2). 
Table 1. Summary of the positional errors for the tags/methods using all comparable days. Absolute errors (|true position-estimate|) and raw errors (|true position-estimate|) are given. Distribution of raw errors were tested for conformity to the normal distribution using the Kolmogorov-Smirnov D test for Goodness of Fit (Sokal and Rohlf, 1981) at the $\mathrm{P}<0.05$ level. Unless indicated as being non-significant (bold-italicised), the remaining tests were significant at $\mathrm{P}<0.05$ (16 of 22 cases).

\begin{tabular}{|c|c|c|c|c|c|c|c|c|c|c|}
\hline \multirow[b]{2}{*}{$\begin{array}{l}\text { Depth } \\
\text { of tag } \\
(\mathrm{m}) \\
\end{array}$} & \multirow[b]{2}{*}{$\begin{array}{l}\text { Common } \\
\text { lat. days } \\
\text { (no.) } \\
\end{array}$} & \multirow[b]{2}{*}{$\begin{array}{c}\text { Common } \\
\text { lon. days } \\
\text { (no.) }\end{array}$} & \multicolumn{2}{|c|}{ NMT } & \multicolumn{2}{|c|}{ Method 1} & \multicolumn{2}{|c|}{ Method 2} & \multicolumn{2}{|c|}{ Method 3} \\
\hline & & & $\begin{array}{c}\text { Mean } \pm \text { SD } \\
\text { lat. errors } \\
\left({ }^{\circ}\right) \\
\end{array}$ & $\begin{array}{c}\text { Mean } \pm \text { SD } \\
\text { lon. errors } \\
\left(^{\circ}\right)\end{array}$ & $\begin{array}{c}\text { Mean } \pm \text { SD } \\
\text { lat. errors } \\
\left({ }^{\circ}\right)\end{array}$ & $\begin{array}{c}\text { Mean } \pm \text { SD } \\
\text { lon. errors } \\
\left({ }^{\circ}\right) \\
\end{array}$ & $\begin{array}{c}\text { Mean } \pm \text { SD } \\
\text { lat. errors } \\
\left({ }^{\circ}\right)\end{array}$ & $\begin{array}{c}\text { Mean } \pm \text { SD } \\
\text { lon. errors } \\
\left({ }^{\circ}\right)\end{array}$ & $\begin{array}{c}\text { Mean } \pm \text { SD } \\
\text { lat. errors } \\
\left({ }^{\circ}\right)\end{array}$ & $\begin{array}{c}\text { Mean } \pm \text { SD } \\
\text { lon. errors } \\
\left({ }^{\circ}\right)\end{array}$ \\
\hline \multicolumn{11}{|c|}{ Absolute } \\
\hline 60 & 163 & 202 & & & $1.49 \pm 2.72$ & $0.15 \pm 0.12$ & $1.83 \pm 2.35$ & $0.16 \pm 0.16$ & $1.70 \pm 5.06$ & $0.25 \pm 0.25$ \\
\hline 58 & 163 & 202 & $5.55 \pm 6.40$ & $0.35 \pm 0.48$ & & & & & & \\
\hline 40 & 317 & 333 & & & $3.50 \pm 4.17$ & $0.19 \pm 0.18$ & $2.15 \pm 1.94$ & $0.23 \pm 0.21$ & $2.33 \pm 2.93$ & $0.25 \pm 0.28$ \\
\hline 24 & 286 & 337 & $1.74 \pm 2.00$ & $0.32 \pm 0.38$ & & & & & & \\
\hline 20 & 286 & 337 & & & $1.53 \pm 2.16$ & $0.20 \pm 0.16$ & $2.10 \pm 1.99$ & $0.23 \pm 0.21$ & $1.41 \pm 1.51$ & $0.25 \pm 0.23$ \\
\hline \multicolumn{11}{|c|}{ Raw } \\
\hline 60 & 163 & 202 & & & $-0.40 \pm 3.08$ & $-0.03 \pm 0.24$ & $-1.20 \pm 2.73$ & $-0.01 \pm 0.23$ & $-0.76 \pm 5.29$ & $0.14 \pm 0.32$ \\
\hline 58 & 163 & 202 & $-4.69 \pm 7.06$ & $-0.14 \pm 0.58$ & & & & & & \\
\hline 40 & 317 & 333 & & & $-0.23 \pm 5.44$ & $-0.04 \pm 0.34$ & $1.19 \pm 2.64$ & $-0.03 \pm 0.31$ & $1.42 \pm 3.46$ & $0.01 \pm 0.37$ \\
\hline 24 & 286 & 337 & $0.95 \pm 2.47$ & $0.04 \pm 0.50$ & & & & & & \\
\hline 20 & 286 & 337 & & & $-1.30 \pm 2.31$ & $0.07 \pm 0.30$ & $0.89 \pm 2.75$ & $0.0 \pm 0.31$ & $0.81 \pm 1.90$ & $0.0 \pm 0.33$ \\
\hline
\end{tabular}


Table 2. Summary of positional errors for the tags/methods using outlier rejection criteria. Absolute errors (true position-estimatel) and raw errors (true position-estimate) are given. Distribution of raw errors were tested for conformity to the normal distribution using the Kolmogorov-Smirnov D test for Goodness of Fit (Sokal and Rohlf, 1981) at the $\mathrm{P}<0.05$ level. Unless indicated as being non-significant (bold-italicized), the remaining tests were significant at $\mathrm{P}<0.05$ (10 of 22 cases).

\begin{tabular}{|c|c|c|c|c|c|c|c|c|c|c|}
\hline \multirow[b]{2}{*}{$\begin{array}{c}\text { Depth of } \\
\text { Tag } \\
(\mathrm{m})\end{array}$} & \multirow[b]{2}{*}{$\begin{array}{c}\text { Common } \\
\text { lat. days } \\
\text { (no.) }\end{array}$} & \multirow[b]{2}{*}{$\begin{array}{c}\text { Common } \\
\text { lon. days } \\
\text { (no.) }\end{array}$} & \multicolumn{2}{|c|}{ NMT } & \multicolumn{2}{|c|}{ Method 1} & \multicolumn{2}{|c|}{ Method 2} & \multicolumn{2}{|c|}{ Method 3} \\
\hline & & & $\begin{array}{c}\text { Mean } \pm \mathrm{SD} \\
\text { lat. errors } \\
\left(^{\circ}\right)\end{array}$ & $\begin{array}{c}\text { Mean } \pm \text { SD } \\
\text { lon. errors } \\
\left(^{\circ}\right)\end{array}$ & $\begin{array}{c}\text { Mean } \pm \mathrm{SD} \\
\text { lat. errors } \\
\left(^{\circ}\right)\end{array}$ & $\begin{array}{c}\text { Mean } \pm \text { SD } \\
\text { lon. errors } \\
\left({ }^{\circ}\right) \\
\end{array}$ & $\begin{array}{c}\text { Mean } \pm \text { SD } \\
\text { lat. errors } \\
\left(^{\circ}\right)\end{array}$ & $\begin{array}{c}\text { Mean } \pm \text { SD } \\
\text { lon. errors } \\
\left(^{\circ}\right)\end{array}$ & $\begin{array}{c}\text { Mean } \pm \text { SD } \\
\text { lat. errors } \\
\left({ }^{\circ}\right)\end{array}$ & $\begin{array}{c}\text { Mean } \pm \text { SD } \\
\text { lon. errors } \\
\left({ }^{\circ}\right) \\
\end{array}$ \\
\hline \multicolumn{11}{|c|}{ Absolute } \\
\hline 60 & 139 & 150 & & & $0.91 \pm 0.91$ & $0.13 \pm 0.09$ & $1.27 \pm 1.25$ & $0.15 \pm 0.13$ & $0.78 \pm 0.74$ & $0.23 \pm 0.17$ \\
\hline 58 & 139 & 150 & $4.42 \pm 3.57$ & $0.29 \pm 0.39$ & & & & & & \\
\hline 40 & 263 & 263 & & & $3.08 \pm 3.74$ & $0.19 \pm 0.18$ & $1.72 \pm 1.28$ & $0.21 \pm 0.18$ & $1.84 \pm 2.25$ & $0.21 \pm 0.19$ \\
\hline 24 & 216 & 241 & $1.50 \pm 1.30$ & $0.29 \pm 0.21$ & & & & & & \\
\hline 20 & 216 & 241 & & & $1.52 \pm 2.21$ & $0.19 \pm 0.15$ & $1.74 \pm 1.82$ & $0.20 \pm 0.18$ & $1.16 \pm 1.26$ & $0.23 \pm 0.19$ \\
\hline \multicolumn{11}{|c|}{ Raw } \\
\hline 60 & 139 & 150 & & & $-0.10 \pm 1.29$ & $-0.06 \pm 0.21$ & $-1.09 \pm 1.41$ & $-0.01 \pm 0.20$ & $0.04 \pm 1.07$ & $0.17 \pm 0.23$ \\
\hline 58 & 139 & 150 & $-3.91 \pm 4.13$ & $-0.08 \pm 0.48$ & & & & & & \\
\hline 40 & 263 & 263 & & & $-0.63 \pm 4.81$ & $-0.06 \pm 0.34$ & $0.87 \pm 1.96$ & $-0.03 \pm 0.27$ & $1.40 \pm 2.54$ & $0.05 \pm 0.28$ \\
\hline 24 & 216 & 241 & $0.64 \pm 1.88$ & $0.08 \pm 0.34$ & & & & & & \\
\hline 20 & 216 & 241 & & & $-1.32 \pm 2.33$ & $0.05 \pm 0.29$ & $0.42 \pm 2.48$ & $0.04 \pm 0.27$ & $0.53 \pm 1.63$ & $0.11 \pm 0.27$ \\
\hline
\end{tabular}


The outlier rejection technique also significantly altered the correlations between raw latitude and longitude errors in 5 of 11 cases for each method (Table 3) except for Method 2. Before and after outlier rejection, there were no obvious patterns in the correlations between latitude and longitude errors for tags by depth or method. We examined the distribution of position estimates with box-and-whiskers plots using the culled dataset (Figure 6). For both latitude and longitude estimates, is apparent that tab/method combinations exhibited mixtures of potential bias and varying degrees of skewness, particularly for the latitude estimates (see also Appendix I). The positional biases of the longitude estimates were similar (Fig. 6).

Table 3. Correlation coefficients between raw latitude and longitude errors for each of the tags/methods where $*=P<0.05, * *=P<0.01$, and $* * * P<<0.001$. "All days" indicates all available days were used as in Table 1. Outliers were removed as in Table 2.

\begin{tabular}{llccc}
\hline NMT & Tag depth & $24 \mathrm{~m}$ & & $58 \mathrm{~m}$ \\
& All days & $-0.1756^{* *}$ & & $-0.1180^{*}$ \\
& outliers removed & 0.0133 & & $-0.1762^{* *}$ \\
\hline \multirow{2}{*}{ Method 1 } & Tag depth & $20 \mathrm{~m}$ & $40 \mathrm{~m}$ & $60 \mathrm{~m}$ \\
& All days & -0.1149 & 0.0699 & -0.0549 \\
& outliers removed & $-0.1678^{*}$ & 0.0200 & $0.1958^{*}$ \\
\hline \multirow{2}{*}{ Method 2 } & Tag depth & $20 \mathrm{~m}$ & $40 \mathrm{~m}$ & $60 \mathrm{~m}$ \\
& All days & 0.1019 & -0.0003 & 0.0384 \\
& outliers removed & 0.0834 & -0.0487 & 0.0706 \\
\hline \multirow{2}{*}{ Method 3 } & Tag depth & $20 \mathrm{~m}$ & $40 \mathrm{~m}$ & $60 \mathrm{~m}$ \\
& All days & -0.0172 & 0.0598 & $-0.3260 * * *$ \\
& outliers removed & 0.0203 & 0.0981 & 0.0726 \\
\hline
\end{tabular}

\section{DISCUSSION}

We assume biofouling accounted for the reduction of maximum light levels recorded over the entire length of the experiment (Fig. 1), although the changes did not appear correlated with depth or season. Compared to the errors induced by the spring and autumnal equinoxes (Fig. 2-5), biofouling did not significantly impede the ability to derive accurate geographical pos itions. For example, Method 3 uses $70 \%$ of the ambient light to estimate positions and thus would not be affected by biofouling. Moreover, we have not found biofouling to be a significant problem in archival tags attached to bigeye tuna (Thunnus obesus), even when fish were at liberty for 272 days (M. Musyl and R. Brill, unpublished observations). 

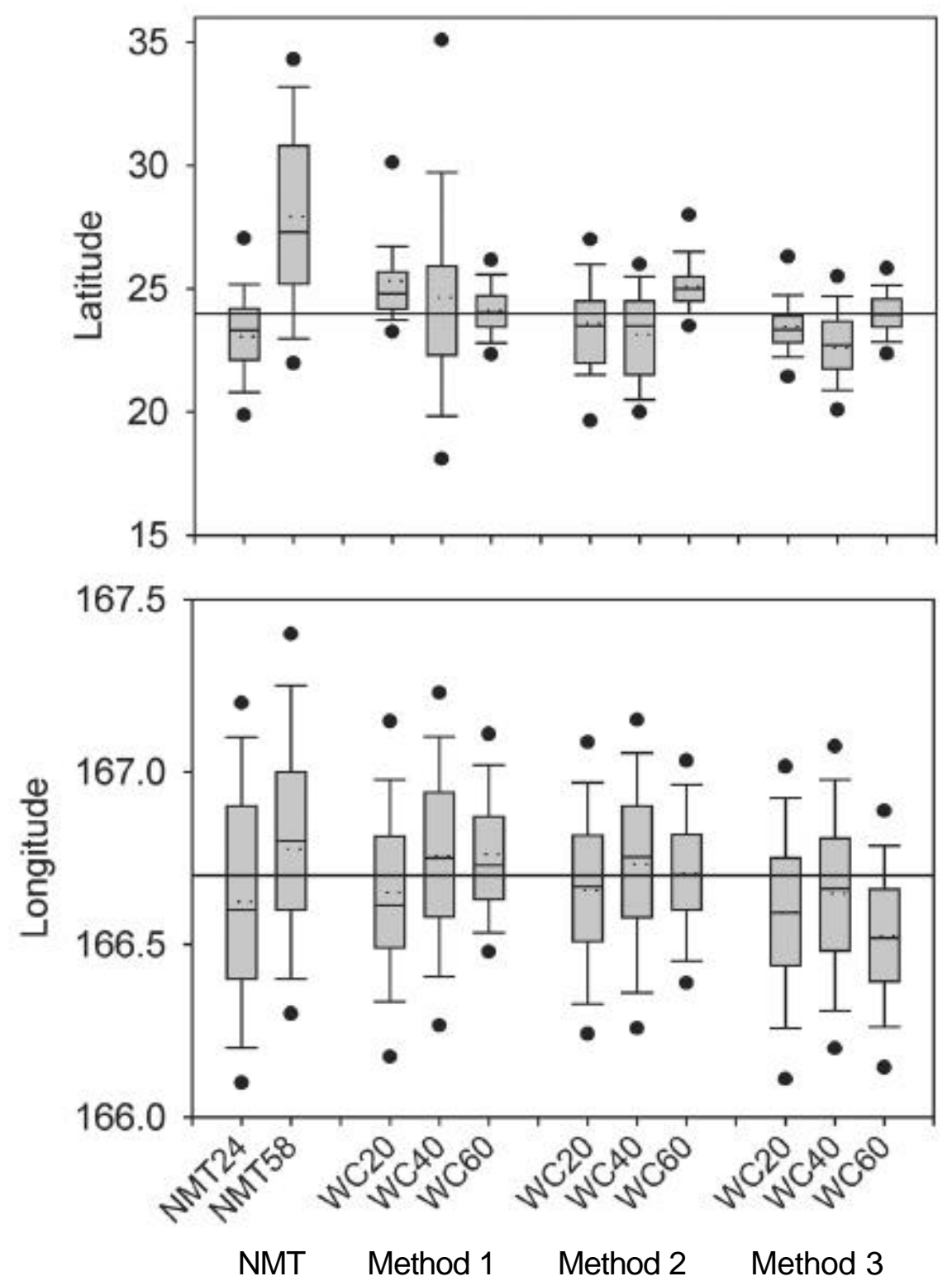

Figure 6. Box and Whiskers plots for the estimated latitude and longitude positions for each tag/method using outlier rejection (as in Table 2). The location of the mooring line is indicated by the horizontal bar across the plots. In the boxes, the horizontal line is the median and the dashed line is the mean. The extremities of the box are the $25^{\text {th }}$ and $75^{\text {th }}$ percentiles and the capped "whiskers" either side represent the $10^{\text {th }}$ and $90^{\text {th }}$ percentiles. The dots represent the $5^{\text {th }}$ and $95^{\text {th }}$ percentiles. 
For all tags and all methods, longitude is always more accurately estimated than latitude. This occurs for several reasons. The estimates of longitude require only an accurate measure of the time of local noon (i.e., the midpoint between dawn and dusk), so any random errors in estimating times of dawn and dusk (e.g., from variable zeniths) will tend to cancel each other. That is, if the rate of data acquisition is set for $60 \mathrm{~s}$ (as for the WC tags), taking the average of dawn and dusk will improve the resolution to 30 s assuming the errors for the dawn and dusk estimates are uncorrelated. However, the more likely scenario is that because of varying cloud cover, the light sensors may respond in a similar manner such that the dawn and dusk errors are serially correlated and $\mathrm{N}$ is not 2 independent degrees of freedom, but some smaller number. For example: $\mathrm{SE}=\mathrm{SD} / \mathrm{sqrt}(\mathrm{N})$, therefore $\mathrm{SE}=0.71 * \mathrm{SD}$; so the SE will lie somewhere between 0.71 and 1, but we are not sure where. Also, an error of 1 minute in estimating the time of local noon results in a longitude error of only $0.25^{\circ}$, regardless of latitude or day of year. In contrast, determination of latitude requires a very precise measurement of day length. For example, at $24^{\circ} \mathrm{N}$ on February 1, an error of 1 minute in day length results in a latitude estimate error of approximately $1^{\circ}$. The situation becomes worse towards the equator and around spring and autumnal equinoxes (Hill, 1994; Welch and Eveson 1999).

The equinox problem occurs because day length is almost the same at all latitudes. As a result, even very small errors in estimating times of dawn and dusk translate into large errors in estimated latitude. This situation is clearly reflected in our data (Figs. 2-5). Longitude estimates remain stable over the 12 month period, whereas latitude estimates vary dramatically about 12 days approximately before and after the equinoxes. Indeed, NMT tags' onboard algorithm could not estimate latitude during these times (Fig. 2).

\subsection{NMT Tags}

In the generation of NMT tags used for this study, no post-processing of the light data is possible. This represents a clear tradeoff. The data returned by the tags already contain geographical position estimates and the storage methodology makes better use of the tag's limited memory. Our results suggest a possible effect of depth on the stability (Fig. 2) and magnitude of mean absolute errors of latitude (Table 1). The NMT tag at 24 m clearly performed better than the tag at $58 \mathrm{~m}$. However, because of the failure of the third NMT tag, we cannot be definitive about systematic errors occurring with depth and our results may simply reflect inter-tag variability.

With moving fish, data will have to be rejected based on some a priori criteria such as a reasonable distance the animal could have moved over a 
given time period. For example, median speed over ground estimated for acoustically tagged tunas ( $\sim 55$ to $165 \mathrm{~cm}$ FL, Brill et al., 1999) ranged from about 80 to $120 \mathrm{~cm} \mathrm{~s}^{-1}$ (i.e. 1.55 to $2.33 \mathrm{nmi} \mathrm{h}^{-1}$ ). At these speeds, fish traveling in a straight line for $24 \mathrm{~h}$ could cover between 37 and $55 \mathrm{nmi}$. In the best of circumstances, several days' of travel in a straight line would be required to cover distances measurable by the current generation of archival tags. In other words, the degree of resolution for current generation archival tags and resultant geopositions cannot distinguish whether a tuna is associated or away from a FAD. But for many fisheries management related questions weekly geopositions are likely to be adequate (e.g., Hilborn and Walters, 1992; Bakun, 1996). Given reasonable fish speeds, weekly positions can easily differ by several degrees of latitude and longitude. Based on these assumptions, we argue that a resolution of $0.5^{\circ}$ longitude and $2^{\circ}$ latitude is acceptable in many instances. For example, using these criteria, mean absolute longitude estimates for all tag/method combinations are within this range or below (Table 2). These spatial scales also have about the same resolution of frontal weather systems and oceanographic eddies (Steele, 1995). Assuming tags are to be used to resolve questions of ocean basin scale movements, latitude estimates are acceptable for the NMT tag at $24 \mathrm{~m}$ and for WC tag/method combinations at 20 and $60 \mathrm{~m}$, in that mean absolute errors were below $2^{\circ}(120 \mathrm{nmi}$ or $222 \mathrm{~km})$ (Table 2$)$.

\subsection{WC Tags}

The WC tags record light levels and thus allow the user to choose an algorithm for estimating geographical positions after retrieval. Post-recovery analysis allows further refinement of position estimates as better algorithms and software are developed. However, this philosophy means that algorithms need to be validated through studies such as ours. To this end, our light level data are available from the Pelagic Fisheries Research Program

web site (http://www.soest.hawaii.edu/PFRP/elec.tagdata/tagdata.html) for investigators wishing to test new geographical positioning algorithms.

Although there were significant effects of depth on mean absolute errors of latitude provided by the WC tags (Table 1), there was no trend. From our data it is not possible to determine whether this result is due to depth, to intrinsic properties of the tag (e.g., light sensor function, voltage stability, etc.), or to some external factor such as different orientation of the light sensor pods, differential shading, etc. Clearly, the possible effects of depth on the accuracy of geographical position estimates need further investigation.

Like the algorithm within the NMT tags, all three algorithms used to process the light le vel data from the WC tags were significantly poorer at estimating latitude around the equinoxes (Figs. 3-5). If fish movements are 
known to be constrained to a defined geographic coastal area, then it may be possible to anchor tags at fixed locations in order to refine zenith angles for that specific study site. This would, in turn, reduce mean absolute errors for latitude for all of the methods presented herein. For example, when we tuned the zenith angle in Method 3 from $94^{\circ}$ to $94.7^{\circ}$, mean absolute errors for latitude were more than halved (Appendix II). However, the reader is cautioned that the accuracy of the results presented in this report may be more dependent on the specific zenith angle chosen than the true merits of the algorithms. For the purpose of tracking migration of oceanic pelagic fishes any of the three methods used with the WC tags would provide a satisfactory track of movements, particularly if used in combination with water temperature at-depth measurements to improve latitude estimates.
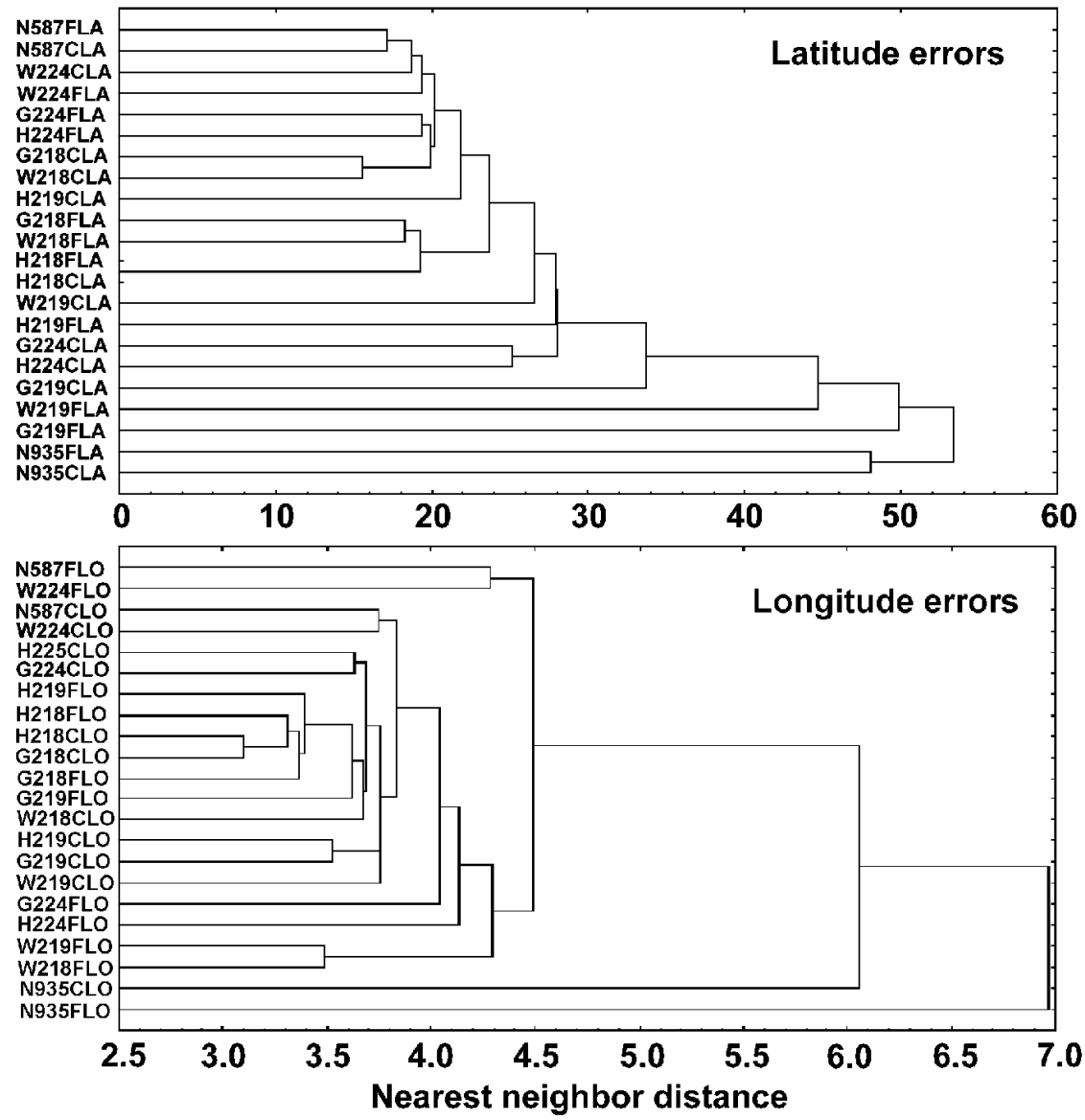

Figure 7. Nearest neighbor clustering using euclidean distance for the raw positional errors. Abbreviations for the tag/method combinations follow those described in Appendix I. 
In this report, we examined 44 possible tag/method combinations and the positional data derived from them (Tables 1 and 2; Appendix I). To explore for patterns in the raw positional errors, we subjected the data to nearest neighbor clustering using Euclidean distance (Fig. 7). In general, methods using the WC tags tended to form the tightest clusters (i.e., branches with smaller distances) for both raw latitude and longitude errors (Fig.7). Yet, it was apparent that there were some striking inter-tag differences among the different tag/method combinations deployed at different depths as indicated in Tables 1 and 2. Still, there was no obvious systematic pattern in the errors.

Whilst it is beyond the scope of this paper to investigate in greater detail the nature of the systematic errors reported herein for each tag/method combination, a few general conclusions can be drawn. Firstly, the outlier rejection techniques used herein significantly reduced mean absolute errors in approximately half the cases. Outlier rejection did not significantly alter the positional bias. However, outlier rejection techniques can dramatically change the distribution of the errors (6 out of 17 cases, Table 2). Outlier rejection may be advantageous in certain instances in that it normalizes the distribution of some of the errors. That advantage may be compromised owing to significant correlation between latitude and longitude errors (Table 3). However, if weather and/or ambient oceanographic conditions were responsible for correlation, both latitude and longitude positional errors might be expected to degrade in unison. Correlation among errors might suggest an external cause for which adjustments could be made. We suggest investigators examine different outlier rejection techniques to find which ones complement their algorithms and minimize the amount of bias in their data.

In this experiment we were unable to examine the effect of depth and diving patterns of fish on the accuracy of position estimates based on light. We know from archival tag data collected by a number of researchers that diving, particularly around the times of dusk and dawn, significantly affects the quality of light data collected by archival tags, and thus the accuracy of position estimates based on light (J. Gunn, unpublished data for southern bluefin tuna, Thunnus macoyii). Our data represent a best-case scenario in estimating position; we stress that much work remains to those working with "real fish data."

We conclude that for questions of fine scale daily movement patterns, currently available archival tags, light data processing algorithms, and the resultant geographical position estimates are not suitable. Resolutions of latitude to only $2^{\circ}$ are likely to be greater than the distance fish will travel over a $24 \mathrm{~h}$ period. As a result, horizontal movement patterns will be undetectable. Acoustic telemetry remains a better technology for resolving questions of finescale movements in relation to specific oceanographic conditions and forage 
densities (Brill et al., 1999; Dagorn et al., 2000). Archival tags, however, are clearly suitable for answering questions of ocean basin scale migration patterns, residency in specific fishing areas, spawning areas, fidelity to natal spawning areas, and possible stock structure. Archival tags are also excellent for recording vertical movement patterns in relation to oceanographic conditions. From these data, conclusions and models of physiological abilities and tolerances can be derived (Brill and Lutcavage, 2001). As both hardware and software improve, we suspect that the use of archival tag technology will become an increasingly important tool in fisheries research.

\section{ACKNOWLEDGEMENTS}

This project was funded by Cooperative Agreements NA37RJ0199 and NA67RJ0154 between the National Oceanic and Atmospheric Administration and the Joint Institute for Marine and Atmospheric Research, University of Hawaii (UH). We thank Drs. Phil Ekstrom of Northwest Marine Technologies and Suzanne Hill of Wildlife Computers for providing comments on an earlier draft. Two anonymous referees provided comments on an earlier draft and Dr. J.R. Sibert, UH, provided comments and suggestions that significantly improved the manuscript. The mooring was deployed from the NOAA ship Ka'imi moana courtesy of Pacific Marine Environmental Laboratory (PMEL) and recovered using the NOAA ship Townsend Cromwell courtesy of NMFS Honolulu Laboratory. We thank officers and crews of both vessels for their outstanding support. We thank Dr. Pierre Flament of UH and Bill Parker, Hugh Milburn, and Rick Miller of NOAA-PMEL for kindly providing mooring equipment, instrumentation, and design assistance. The authors or their agencies do not necessarily approve, recommend, or endorse any proprietary hardware or software mentioned in this publication. The views expressed herein are those of the authors and do not necessarily reflect the views of their agencies.

\section{REFERENCES}

Bakun, A. (1996) Patterns in the Ocean: Ocean Processes and Marine Population Dynamics. California Sea Grant College System, NOAA, 323 pp.

Block, B.A., Dewar, H., Farwell, C., and Prince, E.D. (1998a) A new satellite technology for tracking the movements of the Atlantic bluefin tuna. Proc. Natl. Acad. Sci. USA 95, 93849389.

Block, B.A., Dewar, H., Williams, T., Prince, E.D., Farwell, C., and Fudge, D. (1998b) Archival tagging of Atlantic bluefin tuna (Thunnus thynnus). Mar. Tech. Soc. J. 32, 37-46.

Bowditch, N. (1995) The American Practical Navigator: An Epitome of Navigation Originally by Nathaniel Bowdich (1802), Pub. No. 9. Defense Mapping Agency Hydro- 
graphic/Topographic Center, Bethesda, MD, 873 pp. [also available online http://pollux.nss.nima.mil/pubs/ ].

Brill, R.W., Block, B.A., Boggs, C.H., Bigelow, K.A., Freund, E.V., and Marcinek, D.J. (1999) Horizontal movements and depth distribution of large adult yellowfin tuna (Thunnus albacares) near the Hawaiian Islands, recorded using ultrasonic telemetry: Implications for the physiological ecology of pelagic fishes. Mar. Biol. 133, 395-408.

Brill, R., and Lutcavage, M. (2001) Understanding environmental influences on movements and depth distributions of tunas and billfishes can significantly improve population assessments. In Sedberry, G. ed. Islands in the Stream: Oceanography and Fisheries of the Charleston Bump. American Fisheries Society Symposium 25, Bethesda, MD (in press).

Dagorn, L., Bach, P., and Josse, E. (2000) Movement patterns of large bigeye tuna (Thunnus obesus) in the open ocean determined using ultrasonic telemetry. Mar. Biol. 136, 361-371.

Duffet-Smith, P. (1988) Practical Astronomy with your Calculator, $3^{\text {rd }}$ edition. Cambridge University Press. 129 pp.

Gunn, J., Polachek, T., Davis, T., Sherlock, M., and Betlehem, A. (1994) The development and use of archival tags for studying the migration, behaviour and physiology of bluefin tuna, with an assessment of the potential for transfer of the technology for groundfish research. ICES C.M. Mini, 21.

Hilborn, R. and Walters, C.J. (1992) Quantitative Fisheries Stock Assessment: Choice, Dynamics \& Uncertainty. Chapman and Hall, NY, $570 \mathrm{pp}$.

Hill, R. (1994) Theory of geolocation by light levels. In: LeBoeuf, B.J. and Laws, R.M. eds. Elephant Seals: Population Ecology, Behaviour, and Physiology. University of California Press, Berkeley, CA, pp. 227-236.

Klimley, A.P., Prince, E.D., Brill, R.W., and Holland, K. (1994). Archival Tags 1994: Present and Future. NOAA Technical Memorandum NMFS-SEFSC-357. US Department of Commerce, 42 pp.

Lutcavage, M.E., Brill, R.W., Skomal, G.B., Chase, B.C., and Howey, P.W. (1999) Results of pop -up satellite tagging of spawning size class fish in the Gulf of Maine: do North Atlantic bluefin tuna spawn in the mid-Atlantic? Can. J. Fish. Aquat. Sci. 56, 173-177.

Meeus, J. (1991) Astronomical Algorithms. Willman-Bell, VA, 429 pp.

Metcalfe, J.D., and Arnold, G.P. (1997) Tracking fish with electronic tags. Nature (Lond.) 387, 665-666.

Nielsen, E.T. (1963) Illumination at twilight. Oikos 14, 9-21.

Pielou, E.C. (1984) The Interpretation of Ecological Data. John Wiley, NY, 263 pp.

Sobel, D. (1995) Longitude: The True Story of a Lone Genius Who Solved the Greatest Scientific Problem of His Time. Penguin Books, NY, 184 pp.

Sokal, R.R., and Rohlf, F.J. (1981) Biometry. W.H. Freeman and Company, NY, 859 pp.

Smith, P., and Goodman, D. (1986) Determining fish movements from an "archival" tag: precision of geographical positions made from a time series of swimming temperature and depth. NOAA Technical Memorandum NMFS, NOAA-TM-NMFS-SWFC-60. Southwest Fisheries Science Center, La Jolla, CA, 92038.

Steele, J.H. (1995) Can ecological concepts span the land and ocean domains? In Powell, T.E., and Steele, J.H., eds. Ecological Time Series. Chapman \& Hall, NY, pp. 5-19.

Welch, D.W., and Eveson, J.P. (1999) An assessment of light-based geoposition estimates from archival tags. Can. J. Fish Aquat. Sci. 56, 1317-1327.

Wilson, R.P., Ducamp, J.-J., Rees, W.G., Culik, B.M., and Neikamp, K. (1992) Estimation of location: global coverage using light intensity. In Priede, I.G., and Swift, S.M., eds. Wildlife Telemetry: Remote Monitoring and Tracking of Animals. Ellis Horwood, NY, pp. 131-134. 
Appendix I: Summary statistics for the raw position errors. Abbreviations are as follows: FLA =full latitude days and FLO= full longitude days as in Table 1; CLA=culled latitude days and $\mathrm{CLO}=$ culled longitude days as in Table 2; N587=NMT tag at $24 \mathrm{~m}$; (continued $\Rightarrow$ )

\begin{tabular}{|c|c|c|c|c|c|c|c|c|}
\hline ID & $\mathrm{N}$ & Mean & $\begin{array}{c}\text { C. I. } \\
\pm 95 \%\end{array}$ & $\begin{array}{c}\text { C. I. } \\
\pm 95 \%\end{array}$ & Median & Sum & Min & Max \\
\hline N587FLA & 286 & 0.95 & 0.66 & 1.24 & 0.70 & 272.10 & -6.50 & 18.50 \\
\hline N587CLA & 216 & 0.64 & 0.39 & 0.90 & 0.70 & 139.00 & -6.50 & 4.90 \\
\hline N935FLA & 163 & -4.70 & -5.79 & -3.60 & -3.30 & -765.40 & -53.60 & 9.70 \\
\hline N935CLA & 139 & -3.91 & -4.60 & -3.22 & -3.30 & -543.50 & -17.70 & 3.20 \\
\hline G224FLA & 286 & -1.30 & -1.57 & -1.03 & -0.76 & -372.22 & -16.33 & 2.40 \\
\hline G224CLA & 216 & -1.32 & -1.63 & -1.01 & -0.80 & -284.82 & -16.33 & 2.40 \\
\hline G219FLA & 317 & -0.23 & -0.83 & 0.37 & 0.18 & -73.52 & -22.79 & 24.00 \\
\hline G219CLA & 263 & -0.63 & -1.21 & -0.05 & 0.00 & -165.46 & -22.79 & 9.65 \\
\hline G218FLA & 163 & -0.40 & -0.87 & 0.08 & -0.05 & -64.67 & -21.73 & 8.94 \\
\hline G218CLA & 139 & -0.10 & -0.32 & 0.11 & -0.03 & -14.37 & -5.23 & 4.33 \\
\hline H224FLA & 286 & 0.89 & 0.57 & 1.21 & 1.00 & 255.00 & -11.50 & 10.00 \\
\hline H224CLA & 216 & 0.42 & 0.08 & 0.75 & 0.50 & 90.00 & -11.50 & 10.00 \\
\hline H219FLA & 317 & 1.19 & 0.89 & 1.48 & 1.00 & 376.00 & -7.50 & 13.50 \\
\hline H219CLA & 263 & 0.87 & 0.63 & 1.11 & 0.50 & 229.50 & -3.50 & 6.00 \\
\hline H218FLA & 163 & -1.20 & -1.63 & -0.78 & -1.00 & -196.00 & -12.50 & 11.50 \\
\hline H218CLA & 163 & -1.20 & -1.63 & -0.78 & -1.00 & -196.00 & -12.50 & 11.50 \\
\hline W224FLA & 286 & 0.81 & 0.59 & 1.03 & 0.81 & 232.67 & -12.16 & 11.00 \\
\hline W224CLA & 216 & 0.53 & 0.31 & 0.75 & 0.67 & 114.36 & -12.16 & 6.53 \\
\hline W219FLA & 317 & 1.42 & 1.04 & 1.80 & 1.41 & 450.49 & -18.06 & 23.44 \\
\hline W219CLA & 317 & 1.40 & 1.09 & 1.71 & 1.29 & 368.95 & -6.66 & 23.44 \\
\hline W218FLA & 163 & -0.76 & -1.58 & 0.06 & -0.01 & -123.89 & -53.91 & 6.39 \\
\hline W218CLA & 139 & 0.42 & -0.14 & 0.22 & 0.05 & 5.80 & -3.07 & 4.10 \\
\hline N587FLO & 337 & 0.04 & -0.01 & 0.10 & 0.10 & 14.90 & -5.60 & 1.50 \\
\hline N587CLO & 241 & 0.08 & 0.03 & 0.12 & 0.10 & 18.20 & -1.10 & 1.10 \\
\hline N935FLO & 202 & -0.14 & -0.22 & -0.06 & -0.10 & -27.80 & -3.80 & 3.00 \\
\hline N935CLO & 150 & -0.08 & -0.15 & 0.00 & -0.10 & -11.30 & -1.80 & 3.00 \\
\hline G224FLO & 337 & 0.07 & 0.03 & 0.10 & 0.10 & 21.95 & -1.22 & 0.99 \\
\hline G224CLO & 241 & 0.05 & 0.01 & 0.09 & 0.09 & 11.85 & -1.03 & 0.99 \\
\hline G219FLO & 333 & -0.04 & -0.07 & -0.00 & -0.02 & -12.47 & -2.23 & 1.12 \\
\hline G219CLO & 263 & -0.06 & -0.10 & -0.02 & -0.05 & -14.93 & -2.23 & 1.12 \\
\hline G218FLO & 202 & -0.03 & -0.07 & -0.00 & -0.03 & -6.82 & -0.99 & 0.69 \\
\hline G218CLO & 150 & -0.06 & -0.10 & -0.03 & -0.03 & -9.34 & -0.86 & 0.57 \\
\hline H224FLO & 337 & 0.05 & 0.02 & 0.09 & 0.04 & 17.53 & -1.36 & 1.55 \\
\hline H224CLO & 241 & 0.04 & 0.01 & 0.08 & 0.03 & 10.33 & -0.87 & 1.13 \\
\hline H219FLO & 333 & -0.03 & -0.06 & 0.00 & -0.04 & -9.70 & -1.31 & 1.45 \\
\hline H219CLO & 263 & -0.03 & -0.07 & -0.00 & -0.05 & -8.86 & -1.01 & 1.03 \\
\hline H218FLO & 202 & -0.01 & -0.04 & 0.02 & -0.01 & -1.86 & -0.59 & 0.89 \\
\hline H218CLO & 150 & -0.01 & -0.04 & 0.03 & -0.00 & -0.84 & -0.58 & 0.76 \\
\hline W224FLO & 337 & 0.08 & 0.04 & 0.11 & 0.08 & 25.61 & -2.03 & 0.99 \\
\hline W224CLO & 241 & 0.11 & 0.07 & $0 . .14$ & 0.11 & 25.59 & -0.79 & 0.84 \\
\hline W219FLO & 333 & 0.01 & -0.03 & 0.05 & 0.02 & 3.95 & -2.92 & 1.09 \\
\hline W219CLO & 263 & 0.05 & 0.02 & 0.09 & 0.04 & 13.58 & -0.80 & 1.09 \\
\hline W218FLO & 202 & 0.14 & 0.10 & 0.19 & 0.16 & 29.01 & -2.35 & 1.03 \\
\hline W218CLO & 150 & 0.17 & 0.14 & 0.21 & 0.18 & 26.05 & -0.58 & 0.98 \\
\hline
\end{tabular}


(Appendix continued $\Rightarrow$ ) N935=NMT tag at $58 \mathrm{~m}$; for the Wildlife Computers $=(\mathrm{WC})$ tags; $\mathrm{G}=$ Method 1, H=Method 2, W=Method 3; 224=WC tag at $20 \mathrm{~m}, 219=\mathrm{WC}$ tag at $40 \mathrm{~m}$, $218=\mathrm{WC}$ tag at $60 \mathrm{~m}$.

\begin{tabular}{|c|c|c|c|c|c|c|c|c|c|c|}
\hline $\begin{array}{c}\text { Lower } \\
\text { Quartile } \\
\end{array}$ & $\begin{array}{c}\text { Upper } \\
\text { Quartile } \\
\end{array}$ & Range & $\begin{array}{c}\text { Quartile } \\
\text { Range }\end{array}$ & $\begin{array}{l}\text { Vari- } \\
\text { ance }\end{array}$ & S. D. & S. E. & Skew. & $\begin{array}{r}\text { S. E. } \\
\text { Skew. }\end{array}$ & Kurt. & $\begin{array}{l}\text { S. E. } \\
\text { Kurt. }\end{array}$ \\
\hline-0.20 & 1.90 & 25.00 & 2.10 & 6.11 & 2.47 & 0.15 & 1.79 & 0.14 & 12.23 & 0.29 \\
\hline-0.30 & 1.60 & 11.40 & 1.90 & 3.53 & 1.88 & 0.13 & -0.87 & 0.17 & 2.01 & 0.33 \\
\hline-7.40 & -0.90 & 63.30 & 6.50 & 49.88 & 7.06 & 0.55 & -3.14 & 0.19 & 17.58 & 0.38 \\
\hline-6.80 & -1.20 & 20.90 & 5.60 & 17.02 & 4.13 & 0.35 & -0.74 & 0.21 & 0.74 & 0.41 \\
\hline-1.65 & -0.12 & 18.73 & 1.53 & 5.33 & 2.31 & 0.14 & -2.89 & 0.14 & 11.09 & 0.29 \\
\hline-1.67 & -0.17 & 18.73 & 1.50 & 5.44 & 2.33 & 0.16 & -3.19 & 0.17 & 13.21 & 0.33 \\
\hline-1.96 & 2.01 & 46.79 & 3.97 & 29.55 & 5.44 & 0.31 & -0.40 & 0.14 & 4.54 & 0.27 \\
\hline-1.94 & 1.69 & 32.44 & 3.63 & 23.13 & 4.81 & 0.30 & -1.54 & 0.15 & 4.40 & 0.30 \\
\hline-0.95 & 0.60 & 30.67 & 1.55 & 9.47 & 3.08 & 0.24 & -3.49 & 0.19 & 22.00 & 0.38 \\
\hline-0.72 & 0.56 & 9.56 & 1.28 & 1.65 & 1.29 & 0.11 & -0.18 & 0.21 & 3.24 & 0.41 \\
\hline-0.50 & 2.50 & 21.50 & 3.00 & 7.57 & 2.75 & 0.16 & -0.68 & 0.14 & 3.49 & 0.29 \\
\hline-0.50 & 2.00 & 21.50 & 2.50 & 6.15 & 2.48 & 0.17 & -0.98 & 0.17 & 5.71 & 0.33 \\
\hline-0.50 & 3.00 & 21.00 & 3.50 & 7.00 & 2.64 & 0.15 & 0.82 & 0.14 & 2.54 & 0.27 \\
\hline-0.50 & 2.50 & 9.50 & 3.00 & 3.84 & 1.96 & 0.12 & 0.17 & 0.15 & -0.89 & 0.30 \\
\hline-2.00 & -0.50 & 24.00 & 1.50 & 7.47 & 2.73 & 0.21 & -0.36 & 0.19 & 7.86 & 0.38 \\
\hline-2.00 & -0.50 & 24.00 & 1.50 & 7.47 & 2.73 & 0.21 & -0.36 & 0.19 & 7.86 & 0.38 \\
\hline 0.15 & 1.47 & 23.16 & 1.33 & 3.60 & 1.90 & 0.11 & -0.60 & 0.14 & 10.97 & 0.29 \\
\hline 0.10 & 1.19 & 18.68 & 1.09 & 2.65 & 1.63 & 0.11 & -2.33 & 0.17 & 18.29 & 0.33 \\
\hline 0.30 & 2.50 & 41.50 & 2.20 & 11.98 & 3.46 & 0.19 & 0.05 & 0.14 & 15.70 & 0.27 \\
\hline 0.34 & 2.25 & 30.10 & 1.91 & 6.48 & 2.55 & 0.16 & 4.19 & 0.15 & 33.70 & 0.30 \\
\hline-0.72 & 0.56 & 60.30 & 1.28 & 28.03 & 5.29 & 0.42 & -7.36 & 0.19 & 66.49 & 0.38 \\
\hline-0.57 & 0.56 & 7.17 & 1.12 & 1.15 & 1.07 & 0.09 & 0.42 & 0.21 & 2.28 & 0.41 \\
\hline-0.20 & 0.30 & 7.10 & 0.50 & 0.25 & 0.50 & 0.03 & -4.49 & 0.13 & 49.04 & 0.26 \\
\hline-0.20 & 0.30 & 2.20 & 0.50 & 0.12 & 0.34 & 0.02 & -0.14 & 0.16 & 0.33 & 0.31 \\
\hline-0.30 & 0.10 & 6.80 & 0.40 & 0.33 & 0.58 & 0.04 & -1.09 & 0.17 & 13.02 & 0.34 \\
\hline-0.30 & 0.10 & 4.80 & 0.40 & 0.23 & 0.48 & 0.04 & 1.27 & 0.20 & 12.13 & 0.39 \\
\hline-0.10 & 0.24 & 2.21 & 0.34 & 0.09 & 0.30 & 0.02 & -0.60 & 0.13 & 2.07 & 0.26 \\
\hline-0.11 & 0.21 & 2.02 & 0.32 & 0.08 & 0.29 & 0.02 & -0.44 & 0.16 & 1.78 & 0.31 \\
\hline-0.24 & 0.16 & 3.35 & 0.40 & 0.12 & 0.34 & 0.02 & -0.89 & 0.13 & 5.49 & 0.27 \\
\hline-0.24 & 0.12 & 3.35 & 0.36 & 0.12 & 0.34 & 0.02 & -1.01 & 0. & 6.96 & 0.30 \\
\hline-0.17 & 0.09 & 1.68 & 0.25 & 0.06 & 0.24 & 0.02 & -0.29 & 0.17 & 2.35 & 0.34 \\
\hline-0.18 & 0.07 & 1.43 & 0.24 & 0.04 & 0.21 & 0.02 & -0.77 & 0.20 & 2.26 & 0.39 \\
\hline-0.12 & 0.21 & 2.92 & 0.34 & 0.09 & 0.31 & 0.02 & 0.17 & 0.13 & 2.94 & 0.26 \\
\hline-0.12 & 0.19 & 2.00 & 0.30 & 0.07 & 0.27 & 0.02 & 0.31 & 0.16 & 1.83 & 0.31 \\
\hline-0.20 & 0.13 & 2.76 & 0.34 & 0.09 & 0.31 & 0.02 & 0.23 & 0.13 & 2.68 & 0.27 \\
\hline-0.20 & 0.12 & 2.05 & 0.32 & 0.07 & 0.27 & 0.02 & 0.28 & 0.15 & 1.08 & 0.30 \\
\hline-0.13 & 0.10 & 1.48 & 0.23 & 0.05 & 0.23 & 0.02 & 0.57 & 0.17 & 2.20 & 0.34 \\
\hline-0.12 & 0.10 & 1.34 & 0.22 & 0.04 & 0.20 & 0.02 & 0.26 & 0.20 & 1.44 & 0.39 \\
\hline-0.08 & 0.26 & 3.02 & 0.34 & 0.11 & 0.33 & 0.02 & -1.30 & 0.13 & 6.75 & 0.26 \\
\hline-0.06 & 0.26 & 1.63 & 0.32 & 0.08 & 0.27 & 0.02 & -0.14 & 0.16 & 0.82 & 0.31 \\
\hline-0.15 & 0.21 & 4.01 & 0.37 & 0.14 & 0.37 & 0.02 & -2.06 & 0.13 & 14.68 & 0.27 \\
\hline-0.11 & 0.22 & 1.89 & 0.33 & 0.08 & 0.28 & 0.02 & 0.28 & 0.15 & 1.42 & 0.30 \\
\hline 0.03 & 0.30 & 3.38 & 0.27 & 0.10 & 0.32 & 0.02 & -2.41 & 0.17 & 18.03 & 0.34 \\
\hline 0.03 & 0.30 & 1.56 & 0.27 & 0.05 & 0.23 & 0.02 & 0.04 & 0.20 & 1.44 & 0.39 \\
\hline
\end{tabular}


Appendix II. Summary of positional errors for the WC tags using Method 3 with a zenith angle of $94^{\circ}$. All days (Table 1) and outlier rejection criteria (Table 2) are as before. Absolute errors (|true position-estimate|) and raw errors (|true position-estimate|) are given. Distribution of raw errors were tested for conformity to the normal distribution using the KolmogorovSmirnov D test for Goodness of Fit (Sokal and Rohlf, 1981) at the $\mathrm{P}<0.05$ level. Unless indicated as being non-significant (bold-italicised), the remaining tests were significant at $\mathrm{P}<0.05$ (9 of 12 cases).

\begin{tabular}{|c|c|c|c|c|}
\hline \multicolumn{5}{|c|}{ Absolute Errors } \\
\hline & \multicolumn{2}{|c|}{ Method 3, all days } & \multicolumn{2}{|c|}{ Outliers removed } \\
\hline $\begin{array}{l}\text { Depth of } \\
\operatorname{tag}(\mathrm{m})\end{array}$ & $\begin{array}{c}\text { Mean } \pm \text { SD } \\
\text { lat. errors }\left(^{\circ}\right)\end{array}$ & $\begin{array}{c}\text { Mean } \pm \text { SD } \\
\text { lon. errors }\left({ }^{\circ}\right)\end{array}$ & $\begin{array}{c}\text { Mean } \pm \text { SD } \\
\text { lat. errors }\left(^{\circ}\right)\end{array}$ & $\begin{array}{c}\text { Mean } \pm \mathrm{SD} \\
\text { lon. errors }\left(^{\circ}\right)\end{array}$ \\
\hline 60 & $3.32 \pm 3.89$ & $0.28 \pm 0.48$ & $2.73 \pm 1.44$ & $0.23 \pm 0.17$ \\
\hline 40 & $4.36 \pm 5.78$ & $0.24 \pm 0.24$ & $3.34 \pm 3.15$ & $0.21 \pm 0.19$ \\
\hline 20 & $2.69 \pm 2.11$ & $0.29 \pm 0.83$ & $2.93 \pm 2.09$ & $0.23 \pm 0.19$ \\
\hline \multicolumn{5}{|c|}{ Raw Errors } \\
\hline & \multicolumn{2}{|c|}{ Method 3, all days } & \multicolumn{2}{|c|}{ Outliers removed } \\
\hline $\begin{array}{l}\text { Depth of } \\
\operatorname{tag}(\mathrm{m})\end{array}$ & $\begin{array}{c}\text { Mean } \pm \text { SD } \\
\text { lat. errors }\left({ }^{\circ}\right)\end{array}$ & $\begin{array}{c}\text { Mean } \pm \text { SD } \\
\text { lon. errors }\left(^{\circ}\right)\end{array}$ & $\begin{array}{c}\text { Mean } \pm \text { SD } \\
\text { lat. errors }\left(^{\circ}\right)\end{array}$ & $\begin{array}{l}\text { Mean } \pm \text { SD } \\
\text { lon. errors }\left({ }^{\circ}\right)\end{array}$ \\
\hline 60 & $1.89 \pm 4.76$ & $0.18 \pm 0.52$ & $2.15 \pm 2.22$ & $0.17 \pm 0.23$ \\
\hline 40 & $0.16 \pm 7.24$ & $0.01 \pm 0.34$ & $0.65 \pm 4.55$ & $0.05 \pm 0.28$ \\
\hline 20 & $1.23 \pm 3.19$ & $0.12 \pm 0.87$ & $1.27 \pm 3.37$ & $0.10 \pm 0.27$ \\
\hline
\end{tabular}

